\title{
Textural Stability of Lepidium perfoliatum Seed Gum against Freezing Processes
}

Hadi Bagheri $^{* 1}$, Mahdi Kashaninejad ${ }^{1}$

1- Department of Food Science \& Technology, Gorgan University of Agricultural Sciences and Natural Resources, Gorgan, Iran

\section{A B S T R A C T}

Background and Objectives: Increased frozen food consumptions have led to increased demands for gums with unique properties. Gums are used for the stabilization of food products that undergo various processing. Due to increases in gum use in food industries and high prices of commercial gums, use of native gums has been considered important recently. Therefore, the aim of this study was to assess effects of freezing treatments on textural characteristics of Lepidium perfoliatum seed and xanthan gums at various concentrations.

Materials and Methods: Effects of freezing process at $-18^{\circ} \mathrm{C}$ for $24 \mathrm{~h}$ were investigated on textural characteristics of Lepidium perfoliatum seed gum at various concentrations of $0.50,1.00,1.50$ and $2.00 \%(\mathrm{w} / \mathrm{w})$ and results were compared with those a commercial xanthan gum.

Results: Results showed that hardness, stickiness, consistency and adhesiveness increased significantly by increasing the concentration of gums from 0.50 to $2 \%$ ( $p>0.05$ ). Values of the textural parameters were higher in xanthan gum than Lepidium perfoliatum seed gum. Freezing process at low concentrations of gums led to significant increases in textural parameters $(p<0.05)$. However, textural parameters of gums at higher concentrations decreased after freezing treatments. Xanthan gum included a greater $\mathrm{L}^{*}$ value than that Lepidium perfoliatum seed gum did. Therefore, appearance of xanthan gum was brighter than appearance of Lepidium perfoliatum seed gum. Furthermore, freezing process did not include significant effects on $a^{*}$ and $b^{*}$ values of gums.

Conclusions: Due to the high similarity of Lepidium perfoliatum seed gum with xanthan gum in terms of stability (high stability), the former gum can be considered as an appropriate stabilizing agent under freezing conditions. These findings suggest that Lepidium perfoliatum seed gum, as a stabilizer, can be used in formulation of frozen foods to provide specific functionality, minimize negative effects of freezing and decrease production costs.

Keywords: Lepidium perfoliatum seed gum, Freezing, Stabilizing agent, Xanthan gum

\section{Introduction}

Freezing process is considered as one of the best ways to increase food shelf life and improve chemical and microbiological stabilities of food products (1). Moreover, freezing process disrupts cell or cell components of tissuess due to the formation of ice crystals within the food matrix (2). These ice crystals melt during thawing, which leads to loss of moisture, syneresis, integrity and softening of the texture (3). Despite development of producing frozen foods, texture instability that occurs in frozen foods during freezing processes, is one of the critical problems (4). Gums are used to improve rheological and textural characteristics of frozen foods (5). Typically, gums are used as thickeners to provide foods with appropriate properties in terms of textural and rheological properties (6). Lepidium perfoliatum seeds belong to Cruciferae family, which are originated from countries in the Middle East such as Iran. Seeds of $L$. perfoliatum are significant sources of mucilage and can be used as novel sources of edible gums in food industries due to their high contents of mucilage (7). Because of their convenience of extraction and particular behavior, L. perfoliatum seed gum increasingly been popular as novel sources of edible gums in food sciences (7). Lately, this gum was used for improving textural and rheological properties of foods (8). This gum can be used in food systems because of its high viscosity (9).

Xanthan gum is known as a commercial gum (microbial polysaccharide) that includes unique textural characteristics, compared to other gums. Therefore, it is used as stabilizer in frozen foods (10). Functions of the gums, as stabilizing agents, depend on the gum type and concentration and the process condition, including temperature, time and chemical and physical properties of the foods (11). Hydrocolloids can solve problems caused 
by freezing processes through preserving of the food texture, decreasing $a_{w}$ and limiting the formation of crystalline ice in frozen products (12). Gums can be used to improve or modify food texture, especially under lowtemperature storage conditions (13). Furthermore, gums such as xanthan gum, carrageenan, locust bean gum, guar gum, microcrystalline cellulose (MCC) and carboxymethyl cellulose (CMC) can be used as texture modifiers in frozen foods (14). Gums can decrease disastrous effects of freezing and improve water holding capacity in foods; therefore, they can be used in frozen foods. Gums can control ice crystal growth during the freezing process by decreasing volume of free water, immobilizing the water within the gel structure and controlling moisture immigration (15) and hence can be used in frozen foods. Therefore, the ideal gum for frozen food products needs to include gel or gel-like characteristics that can form threedimensional networks to restrict water mobility through junction zone formations or polyionic complexes $(16,17)$. Use of gums such as cress seed gum, Balangu seed gum and sweet potato starch for the protection of foods during the freezing process has been reported in several studies by Naji et al. (2013), Khodaei et al. (2014), Lee et al. (2002), Maity et al. (2011) and Park et al. (2006) (13, 18, 14, 19, 20).

Effects of freezing processes on viscosity and consistency of the gums as Pseudomonas olevoranse, flaxseed gum and basil seed gum have been reported by Freitas et al. (2009) (21), Hu et al. (2020) (1) and Zeynali et al. (2019) (15). Furthermore, effects of freezing processes on textural attributes of gums such as alginate, basil seed gum and cress seed gum have been reported by Roopa and Bhattacharya (2010), Zameni et al. (2015) and Naji et al. (2013) $(22,13,23)$. However,; no published information on effects of freezing treatments on behaviors of $L$. perfoliatum seed gum is available; therefore, study of freezing properties is essential to assess ability of $L$. perfoliatum seed gum in food formulations. Since use of gums in food industries has increased recently and commercial gums are quite expensive, use of native gums is important. Therefore, investigation of native gums and comparison of them with commercial gums (xanthan gum) in various processes in industries are important as well. The aim of this study was to assess effects of freezing treatments $\left(-18^{\circ} \mathrm{C}\right.$ for $\left.24 \mathrm{~h}\right)$ on textural characteristics of $L$. perfoliatum seed and xanthan gums at various concentrations $(0.50,1,1.5$ and $2 \% \mathrm{w} / \mathrm{w})$.

\section{Materials and Methods}

\section{Materials}

Seeds of $L$. perfoliatum were purchased from medicinal herb markets in Mashhad, Iran. Xanthan gum was purchased from Sigma Chemical, USA.

\section{Methodology}

\section{Extraction method}

The L. perfoliatum seed gum extraction was carried out based on a method described by Koocheki et al. (2009). In brief, $L$. perfoliatum seed gum was extracted from whole seeds using water under optimum condition $\left(\mathrm{T}, 48{ }^{\circ} \mathrm{C} \pm 1\right.$; $\mathrm{pH} 8$, proportion of water to seed, $30: 1 ; \mathrm{t}, 1.5 \mathrm{~h}$ ). The $\mathrm{pH}$ was monitored continuously and adjusted by addition of $0.1 \mathrm{M} \mathrm{l}^{-1} \mathrm{NaOH}$ and/or $\mathrm{HCl}$. Water was preheated to desired temperature before the seeds were added. The seedwater slurry was stirred using electric mixing paddle through the entire extraction time. Seeds were discarded and dispersion was dried at $45{ }^{\circ} \mathrm{C}$ overnight, milled and sieved using mesh-18 sifter (7).

\section{Freezing process}

The L. perfoliatum seed and xanthan gum solutions $(\mathrm{w} / \mathrm{w})$ were prepared in $0.50,1.00,1.50$ and $2.00 \%(\mathrm{w} / \mathrm{w})$ concentrations for textural experiments. The $L$. perfoliatum seed and xanthan gum solutions were frozen at -18 for $24 \mathrm{~h}$ and then thawed at $25{ }^{\circ} \mathrm{C}$ for $10 \mathrm{~h}$. All samples were prepared at three replicates.

\section{Textural properties}

For the study of textural properties of gums, penetration experiments were carry out using TA.XT Texture Analyzer Device (TA-XT Plus Model, UK). A circular probe $(6 \mathrm{~mm})$ with $100 \mathrm{~mm} \mathrm{~min}^{-1}$ rate and $25 \mathrm{~mm}$ depth was used (23). During penetration experiment, force dropped at the point, where the gel broke and resulting forces were due to the continuing penetration up to the demanded depth. Hardness, stickiness, consistency and adhesiveness parameters were calculated from the penetration curve (24). Hardness was the maximum force value in the force-time curve (Fig. 1). The greatest force in negative part of the graph was introduced as stickiness. The positive area under the graph was reported as the adhesive A1 and the negative area as adhesive A2.

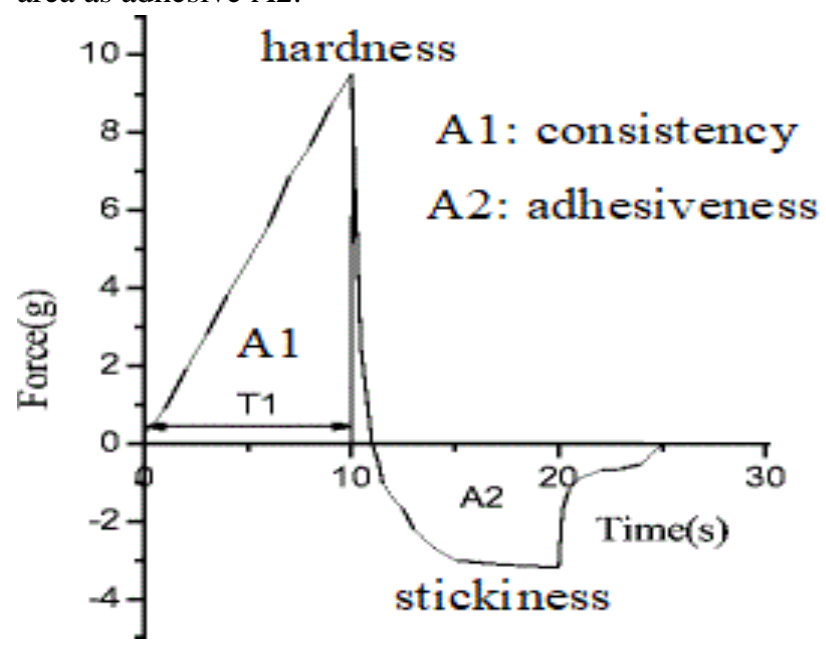

Figure 1. Penetration test and texture analysis for hardness, stickiness, consistency and adhesiveness of gums 


\section{Color analysis}

A computer vision system with a digital camera (Panasonic Lumix DMC-FS42, Japan) was used to measure the color of gum solutions. The $\mathrm{L}^{*} \mathrm{a} * \mathrm{~b} *$ space was used for the description of color samples. Shifts in the space from RGB to $\mathrm{L}^{*} \mathrm{a} * \mathrm{~b} *$ were assisted using Image $\mathrm{J}$ software v.1.42e (ImageJ, Maryland, USA). Three values were used to express the color of the sample, including $L^{*}$ for the lightness from black (0) to white (100), $a^{*}$ for the lightness from green $(-120)$ to red $(+120)$ and $b^{*}$ for the lightness from blue $(-120)$ to yellow $(+120)(25)$.

\section{Statistical analysis}

Full factorial design was used in the experiments. Data were means of three replications and subjected to analysis variance (ANOVA) using Minitab software v.19 (Minitab, USA). Furthermore, significant differences $(p<0.05)$ between the results were identified and $p<0.05$ was considered as significant.

\section{Results and Discussion}

\section{Hardness}

The maximum force observed in the force-time curve during the textural examination was reported as the hardness. Typically, the hardness is a measurement to express the stability of the gel solution under pressure and represents the gel hardness. $(23,24)$. The hardness values of $L$. perfoliatum seed and xanthan gels are shown in Table 1. Based on the Table 1, hardness value of the $L$. perfoliatum seed gum solution increased significantly ( $p<$ 0.05 ) from 12.44 to $31.32 \mathrm{~g}$ by increasing the level of $L$. perfoliatum seed gum from 0.5 to $2 \%$. Increasing concentration of xanthan gum led to an increase of $22.96 \%$ in the hardness value, which was similar to that reported by Hosseini-Parvar et al. (2010) (26). The hardness value of xanthan gum solution was higher than that of $L$. perfoliatum seed gum solution and the highest value of hardness was seen for $2 \%(\mathrm{w} / \mathrm{w})$ concentration of xanthan gum $(44.96 \mathrm{~g})$. The freezing process at $0.5 \%$ concentration in L. perfoliatum seed and xanthan gum solutions included significant effects $(p<0.05)$ on hardness value of the samples, altering from 12.44 to $14.84 \mathrm{~g}$ and from 13.64 to $15.38 \mathrm{~g}$, respectively. This revealed improvement of $L$. perfoliatum seed and xanthan gum strengths (15) (Table 1). At higher concentrations ( 1 and 1.5\%), effects of freezing process were not effective significantly and hardness of the L. perfoliatum seed gum solution was constant. This was observed at $1 \%$ concentration of xanthan gum and the freezing process did not significantly affect hardness of the gum solution $(p<0.05)$ (Table 1). It can be concluded that freezing treatments included no destructive effects on internal bonds linked to the body of $L$. perfoliatum seed and xanthan gums (15). At $2 \%$ concentration of $L$. perfoliatum seed gum solution and 1.5 and $2 \%$ concentrations of xanthan gum solutions, effects of freezing process significantly decreased hardness of the gum solutions $(p<0.05)$ (Table 1$)$.

After freezing, hardness values of the gum solution at low concentrations showed increases, which reveals the improvement of L. perfoliatum seed gel strength (15) (Table 1). At high concentrations, hardness values of the gum solution decreased after the freezing process. Similar results are associated to increased gum hardness after the freezing process for tamarind seed kernels-sugar gum solution, tapioca-xanthan gum solution, curdlan-locust bean gum mixture and xanthan gum (17, 27, 28). Investigating effects of freezing process on sago and potato gels, Teng et al. (2013) showed that hardness of the gel increased significantly after freeze-thaw cycles (4). The researchers showed that hardness of the gel was resulted from the formation of more associations of chains. One reason for the increases in hardness of the gum solutions at low concentrations is possibly linked to the formation of clusters or regular groups within polysaccharide molecules during freezing process. In addition, freezing process led to the accumulation of joining points, which resulted in formation of hard gum solution structures (19) and suggested that $L$. perfoliatum seed gum included a high ability in controlling ice crystal growth. Hence, the texture showed the minimum damage after freezing process. However, freezing might lead to partial degradation of the gum solution network at high concentrations, resulting in decreases in hardness of the gum solutions.

Table 1. Effects of freezing process on hardness of gum solution $(\mathrm{g})$

\begin{tabular}{|c|c|c|c|}
\hline Type of gums & Gum concentration $(\%)$ & Before the freezing process & After the freezing process \\
\hline \multirow{4}{*}{ LPS gum } & 0.5 & $12.44_{\mathrm{d}}^{\mathrm{b}}$ & $14.84_{\mathrm{d}}^{\mathrm{a}}$ \\
\hline & 1 & $15.82^{a}{ }^{a}$ & $15.93^{a}$ \\
\hline & 1.5 & $21.17_{\mathrm{b}}^{\mathrm{a}}$ & $21.94_{\mathrm{b}}^{\mathrm{a}}$ \\
\hline & 2 & $31.32_{\mathrm{a}}^{\mathrm{a}}$ & $28.91_{\mathrm{a}}^{\mathrm{b}}$ \\
\hline \multirow{4}{*}{ xanthan gum } & 0.5 & $13.64_{\mathrm{d}}^{\mathrm{b}}$ & $15.38_{\mathrm{d}}{ }^{\mathrm{a}}$ \\
\hline & 1 & $23.68_{c}{ }^{a}$ & $24.15_{\mathrm{c}}^{\mathrm{a}}$ \\
\hline & 1.5 & $34.05_{\mathrm{b}}{ }^{\mathrm{a}}$ & $31.65_{\mathrm{b}}^{\mathrm{b}}$ \\
\hline & 2 & $44.96_{\mathrm{a}}^{\mathrm{a}}$ & $40.92_{\mathrm{a}}^{\mathrm{b}}$ \\
\hline
\end{tabular}

The letter of power: The average comparison in each row (The effect of the freezing process in a sample with constant concentration), different letters in a row indicate significant differences at $\mathrm{p}<0.05$. The letter of subscript: Average comparison in each column (The effect of different concentrations), different letters in a column indicate significant differences at $\mathrm{p}<0.05$. 


\section{Stickiness}

The utmost force is needed to dominate adhesions between the area of foods and probes, which is considered as stickiness (29). In graphs of the force-time study of the gum texture properties, the greatest force in the negative part of the graph is introduced as stickiness (30). In this study, the stickiness values in a gum solution varied from 5.46 to $-20.66 \mathrm{~g}$. The highest stickiness before freezing process was linked to the gum solution prepared with $2 \%$ concentration of xanthan gum (-19.36 g). As shown in Table 2, stickiness of the gums significantly increased by increasing concentration of gums and the highest stickiness value was observed in xanthan gum. Study of the effects of freezing process on stickiness showed that the freezing process in L. perfoliatum seed gum solution did not include significant effects on stickiness $(p<0.05)$ (Table 2). This stickiness could show the strength of internal bonds of $L$. perfoliatum seed gum gels. These results demonstrated improvement effects of freezing on the junction zone of $L$. perfoliatum seed gum polymers. The stickiness value of xanthan gum significantly increased after freezing treatments $(p<0.05)$ (Table 2). Strength of the internal links in xanthan gum solution increased after freezing (Table 2). Based on a study by Faydi et al. (2001), gels formed at $-60{ }^{\circ} \mathrm{C}$ were significantly stronger than gels formed at $-20{ }^{\circ} \mathrm{C}$ due to the smaller size of the ice crystals (31).

\section{Consistency}

Consistency is defined as a space below the contour up to the objective deformation (24). Based on the Table 3, consistency values of $L$. perfoliatum seed and xanthan gel solutions increased with increasing concentrations of the gums, similar to hardness values. As shown in Table 3, consistency values of the $L$. perfoliatum seed gum solution increased significantly ( $p<0.05$ ) from 101.74 to 199.57 g.s by increasing concentration of $L$. perfoliatum seed gum from 0.5 to $2 \%$ and concentration of xanthan gum from 0.5 to $2 \%$, resulting in a 229 g.s increase in consistency value. Consistency values of $L$. perfoliatum seed gum gel solutions increased after freezing process at low concentrations $(0.5,1$ and $1.5 \%)$. At high concentrations of L. perfoliatum seed gel solutions, significant decreases were seen in consistency values (from 199.57 to 186.75 g.s) $(p>0.05)$. After freezing process, consistency values of 0.5 and $1 \%$ low concentrations of xanthan gel included 94.13 and 162.71 g.s, which were mildly increased to 98.95 and 166.13 g.s, respectively. At higher concentrations of xanthan gum (1.5 and 2\%), consistency values decreased from 251.68 to 20.48 and from 323.12 to 268.99 g.s, respectively.

This demonstrated formations of stronger threedimensional networks in L. perfoliatum seed gum gels during freezing that was stable after thawing. Therefore, $L$. perfoliatum seed gum chain bonds were enhanced after freezing and retained $L$. perfoliatum seed gum gel structure after the first compression, improving its ability to sustain the gel shape. Based on the importance of shape sustainability after freezing treatments, it is necessary to use gels that are stable after thawing, resulting in stable texture in frozen foods (15). Naji et al. (2013) showed that the novel cress seed gum included a high stability rate that made it an attractive gum for using in frozen foods (13). Formation of further constant gum solutions at low freezing temperatures was possibly due to the greater conversions of water to ice crystals (29). To protect quality of the frozen products, L. perfoliatum seed gums can be used due to their ability to form further constant gum solutions.

Table 2. Effects of freezing process on stickiness of gum solution $(\mathrm{g})$

\begin{tabular}{cccc}
\hline Type of gums & Gum concentration $(\%)$ & Before the freezing process & After the freezing process \\
\hline \multirow{2}{*}{ LPS gum } & 0.5 & $-5.46_{\mathrm{d}}{ }^{\mathrm{a}}$ & $-6.01_{\mathrm{c}} \mathrm{a}^{\mathrm{a}}$ \\
& 1 & $-7.09_{\mathrm{c}}{ }^{\mathrm{a}}$ & $-6.44_{\mathrm{c}}{ }^{\mathrm{a}}$ \\
& 1.5 & $-8.95_{\mathrm{b}}{ }^{\mathrm{a}}$ & $-8.51_{\mathrm{b}}{ }^{\mathrm{a}}$ \\
& 2 & $-12.03_{\mathrm{a}}{ }^{\mathrm{a}}$ & $-11.46_{\mathrm{a}}{ }^{\mathrm{a}}$ \\
& 0.5 & & $-7.86_{\mathrm{d}}{ }^{\mathrm{a}}$ \\
xanthan gum & 1 & $-6.11_{\mathrm{d}}{ }^{\mathrm{b}}$ & $-12.87_{\mathrm{c}}{ }^{\mathrm{a}}$ \\
& 1.5 & $-11.55_{\mathrm{d}}{ }^{\mathrm{b}}$ & $-15.60_{\mathrm{b}}{ }^{\mathrm{a}}$ \\
& 2 & $-14.51_{\mathrm{b}}{ }^{\mathrm{b}}$ & $-20.66_{\mathrm{a}}{ }^{\mathrm{a}}$ \\
\hline
\end{tabular}

The letter of power: The average comparison in each row (The effect of the freezing process in a sample with constant concentration), different letters in a row indicate significant differences at $\mathrm{p}<0.05$. The letter of subscript: Average comparison in each column (The effect of different concentrations), different letters in a column indicate significant differences at $\mathrm{p}<0.05$. 
Hadi Bagheri and Mahdi Kashaninejad: Textural stability of Lepidium Perfoliatum seed gum

Table 3. Effects of freezing process on consistency of gum solution (g.s)

\begin{tabular}{|c|c|c|c|}
\hline Type of gums & Gum concentration $(\%)$ & Before the freezing process & After the freezing process \\
\hline \multirow{4}{*}{ LPS gum } & 0.5 & $101.74_{d}^{b}$ & $106.86_{\mathrm{d}}^{\mathrm{a}}$ \\
\hline & 1 & $105.91_{\mathrm{c}}^{\mathrm{b}}$ & $110.35_{c}^{a}$ \\
\hline & 1.5 & $136.36_{\mathrm{b}}^{\mathrm{b}}$ & $152.42_{\mathrm{b}}^{\mathrm{a}}$ \\
\hline & 2 & $199.57_{\mathrm{a}}^{\mathrm{a}}$ & $186.75_{\mathrm{a}}^{\mathrm{b}}$ \\
\hline \multirow{4}{*}{ xanthan gum } & 0.5 & $94.13_{\mathrm{d}}^{\mathrm{b}}$ & $98.95_{\mathrm{d}}^{\mathrm{a}}$ \\
\hline & 1 & $162.71_{\mathrm{c}}^{\mathrm{b}}$ & $166.13_{\mathrm{c}}^{\mathrm{a}}$ \\
\hline & 1.5 & $251.68_{\mathrm{b}}^{\mathrm{a}}$ & $220.48_{b}^{b}$ \\
\hline & 2 & $323.12_{\mathrm{a}}^{\mathrm{a}}$ & $268.99^{\mathrm{b}}$ \\
\hline
\end{tabular}

The letter of power: The average comparison in each row (The effect of the freezing process in a sample with constant concentration), different letters in a row indicate significant differences at $\mathrm{p}<0.05$. The letter of subscript: Average comparison in each column (The effect of different concentrations), different letters in a column indicate significant differences at $\mathrm{p}<0.05$.

\section{Adhesiveness}

Potency of the gum solution samples to become sticky is called adhesiveness and the negative area under the graph is reported as an adhesive sample (13, 32, 33). Adhesiveness may be considered a positive or a negative characteristics. For example, adhesiveness is favorable in salad dressings, puddings and confectionary and bakery products, while it is unfavorable in spaghetti and other pasta products, bread crumbs and meat products (34). This factor is critical because it may affect appearance, final quality and shelf life of foods (13). The viscous parameter is a positive factor in bakery products and puddings and a negative factor in products such as spaghetti and meat products (34). In this study, the highest value of adhesive was linked to xanthan gum with a content of $2 \%$, equally to 161 g.s. Moreover, the smallest value of adhesive was linked to L. perfoliatum seed gum with a content of $0.5 \%$ before the freezing process. Generally, xanthan gum was more adhesive than L. perfoliatum seed gum (Table 4). These findings were similar to findings by Koocheki et al. (2013) (18).

Adhesiveness values of the $L$. perfoliatum seed gum solution increased after freezing at low concentrations $(0.5$ and $1 \%$ ). This result revealed improvement effects of freezing on the junction zone of $L$. perfoliatum seed gum polymers. Teng et al. (2013) reported that sago starch-sugar gels processed at higher freezing rates included higher adhesiveness rates. At high concentrations, especially 1.5 and $2 \%$, effects of freezing process resulted in decreased adhesive values of the $L$. perfoliatum seed gum solution ( $p$ $<0.05$ ) (Table 4). In $0.5,1$ and $1.5 \%$ concentrations of the xanthan gum solution, effects of freezing process increased adhesive values. In contrast, freezing process did not include significant effects on the adhesiveness value of xanthan gum at higher concentrations (2\%). Therefore, $2 \%$ xanthan gum can be used in formulation of frozen foods; in which, adhesion is an important factor. Generally, freezing increased the adhesiveness values of $L$. perfoliatum seed and xanthan gum solutions at their low concentrations.
These findings were similar to findings by Williams et al. (2009) for curdlan/xanthan gels (28).

\section{Effects of freezing process on color}

Color is a very important parameter in the quality of food because it can affect the consumer's decision to buy and is probably the first quality factor that is judged. Color plays a key role in food selection and is one of the most important parameters for the consumer (25). As $L$. perfoliatum seed gum would likely be used as a food additive, its color is an important factor as this affects the appearance of products. The effect of the freezing process on the L* of L. perfoliatum seed and xanthan gum solutions is shown in Fig. 2. The concentration was found to have a significant effect on the $\mathrm{L}^{*}$ of $L$. perfoliatum seed and xanthan gums. Xanthan gum had more $L^{*}$ value than $L$. perfoliatum seed gum, therefore the appearance of xanthan gum was brighter than L. perfoliatum seed gum. Fig 2 reveals that increasing concentration from 0.5 to $2 \%$ caused a decrease in $L^{*}$ values from 86 to 58 and 73 to 63 for $L$. perfoliatum seed and xanthan receptivity.

The freezing process in 0.5 and $1 \%$ concentrations in $L$. perfoliatum seed and xanthan gum solution had a significant impact $(p<0.05)$ on the $\mathrm{L}^{*}$ value of samples and it altered from 86 to 58 and 73 to 62 respectively (Fig. 2). Similar results were observed in the studies by Zameni et al. (2015). With increasing the consistency of $L$. perfoliatum seed gum during freezing, the particle concentration increases, therefore lightness decreases because low light is multiply scattered backwards by the droplets (23). At the higher concentrations (2\%), the effect of freezing process did not affect significantly and the $\mathrm{L}^{*}$ value of the $L$. perfoliatum seed gum solution is almost constant. Also, this state was observed at 1.5 and $2 \%$ concentration of xanthan gum, and the effect freezing process was not significant effect on the $\mathrm{L}^{*}$ value $(p<0.05)$ (Fig. 2). 
Hadi Bagheri and Mahdi Kashaninejad: Textural stability of Lepidium Perfoliatum seed gum

Table 4. Effects of freezing process on adhesiveness of gum solution (g.s)

\begin{tabular}{|c|c|c|c|}
\hline Type of gums & Gum concentration $(\%)$ & Before the freezing process & After the freezing process \\
\hline \multirow{4}{*}{ LPS gum } & 0.5 & $-4.97_{\mathrm{d}}^{\mathrm{b}}$ & $-6.19_{\mathrm{d}}^{\mathrm{a}}$ \\
\hline & 1 & $-9.04_{c}^{a}$ & $-8.39^{a}{ }^{a}$ \\
\hline & 1.5 & $-36.46_{b}^{b}$ & $-23.91_{b}{ }^{a}$ \\
\hline & 2 & $-80.31_{\mathrm{a}}{ }^{\mathrm{a}}$ & $-61.50_{a}^{b}$ \\
\hline \multirow{4}{*}{ xanthan gum } & 0.5 & $-17.75_{d}^{b}$ & $-19.05_{\mathrm{d}}{ }^{\mathrm{a}}$ \\
\hline & 1 & $-70.35_{c}^{b}$ & $-91.38_{c}^{a}$ \\
\hline & 1.5 & $-113.46_{b}^{b}$ & $-149.60_{b}{ }^{a}$ \\
\hline & 2 & $-160.02_{a^{a}}^{a}$ & $-161.68_{\mathrm{a}}^{\mathrm{a}}$ \\
\hline
\end{tabular}

The letter of power: The average comparison in each row (The effect of the freezing process in a sample with constant concentration), different letters in a row indicate significant differences at $\mathrm{p}<0.05$. The letter of subscript: Average comparison in each column (The effect of different concentrations), different letters in a column indicate significant differences at $\mathrm{p}<0.05$.

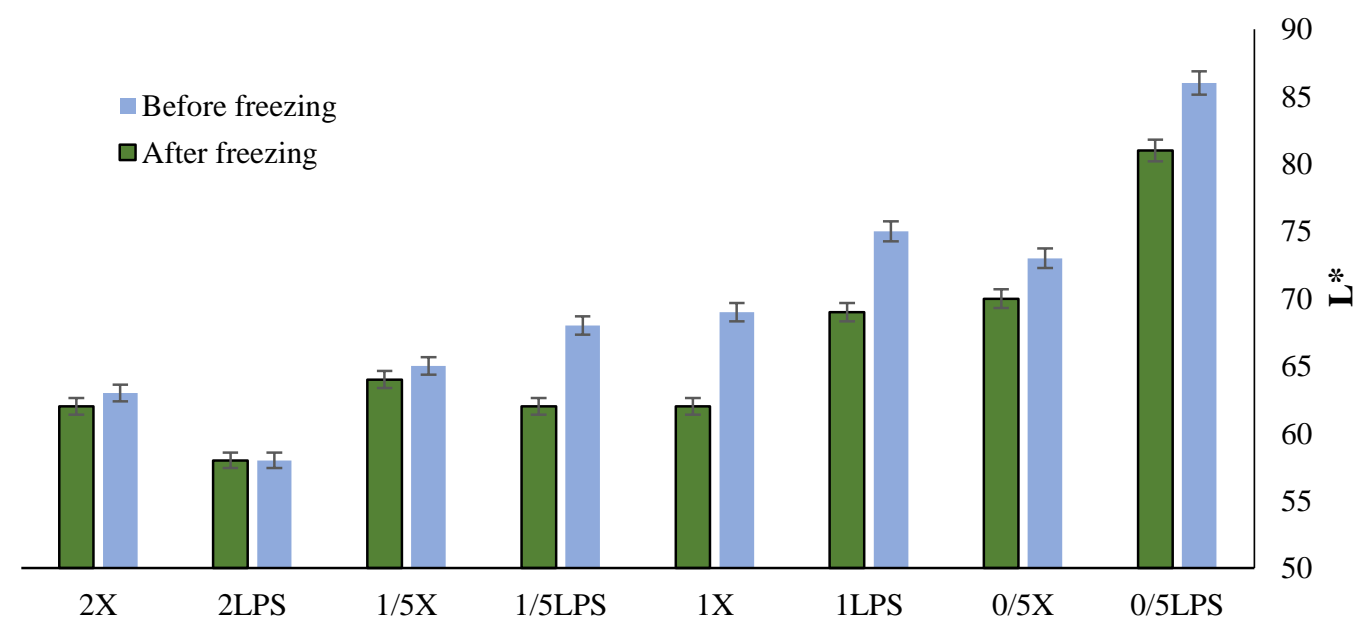

Figure 2. Effects of concentration and freezing process on L* of Lepidium perfoliatum seed and xanthan gum solutions

The $\mathrm{a}^{*}$ value of the L. perfoliatum seed gum solution significantly decreased with increasing concentration, while significant differences were not observed between samples of xanthan gum solution (Fig. 3). Also, freezing process did not have influence on $\mathrm{a}^{*}$ value of $L$. perfoliatum seed and xanthan gums. The $b^{*}$ value of $L$. perfoliatum seed and xanthan significantly increased by increasing concentration, whiles, the freezing process did not have a noticeable effect on the $b^{*}$ value of $L$. perfoliatum seed and xanthan gums (Fig. 4). Finding by the present study are similar to those by Zameni et al. (2015), who reported that the freezing process didn't have noticeable effect on color index (23).

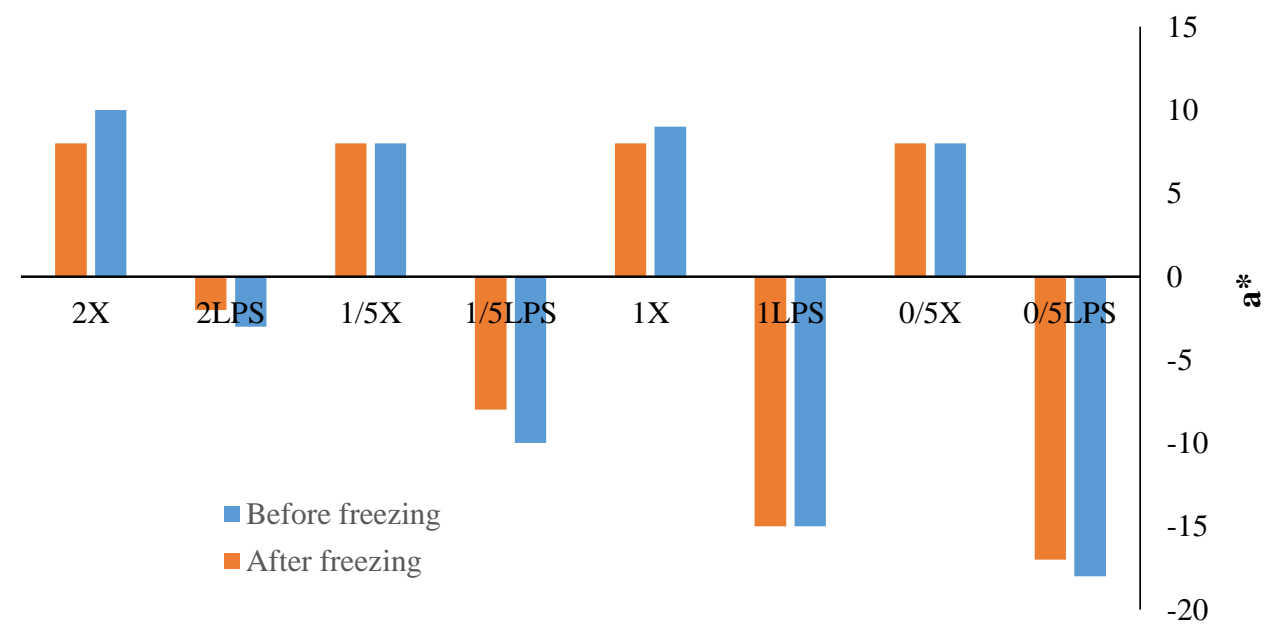

Figure 3. Effects of concentration and freezing process on a* of Lepidium perfoliatum seed and xanthan gum solutions 


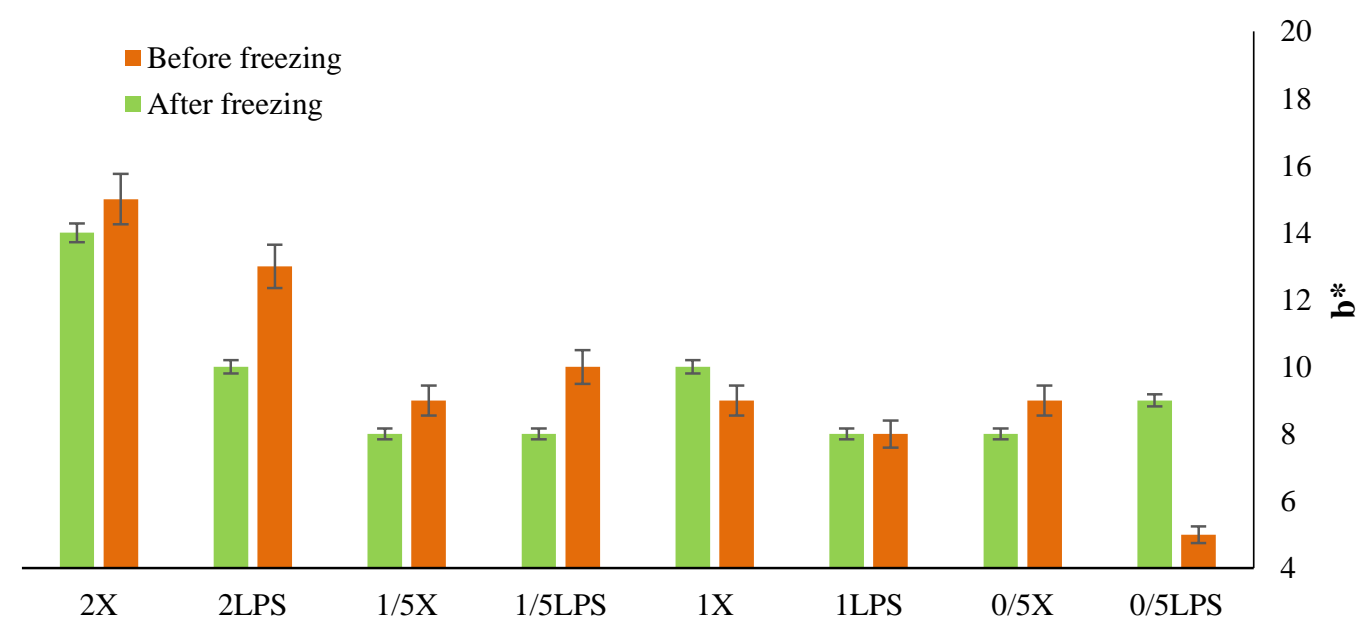

Figure 4. Effects of concentration and freezing process on b* of Lepidium perfoliatum seed and xanthan gum solutions

\section{Conclusions}

According to the results, it can be admitted that in low concentrations, the effect of freezing process resulted in improved textural properties of $L$. perfoliatum seed and xanthan gum solution and in high concentrations, the effect of freezing resulting in a decrease in some of textural properties. Investigations showed that most of the textural properties of xanthan gum solution are better than the $L$. perfoliatum seed gum solution, but the general trend in both gum solutions is equal and both gum solution s exhibit similar behavior in relation to each other. Due to the similarity of L. perfoliatum seed gum with xanthan gum and its high hardness, the use of this gum in frozen foods is promising. Due to the high price of commercial gum, the production and testing of native gum is of high importance. The L. perfoliatum seed gum seed is considered to be an Iranian seed containing large amounts of hydrocolloids with proper textural and rheological properties, it is therefore possible to use L. perfoliatum seed gum as a commercial gum in food. The rheological characteristic of L. perfoliatum seed gum is quite similar to commercial xanthan gum, therefore this gum might be applied as a commercial xanthan gum. According to the result of this investigation, L. perfoliatum seed gum can be investigated more to apply in frozen foods like ice cream, frozen dessert, minced fish and meat products for its high water binding ability.

\section{Acknowledgement}

The authors thank Gorgan University of Agricultural Sciences and Natural Resources for their supports.

\section{Financial disclosure}

The authors declare no conflict of interest.

\section{Funding/Support}

This work was financially supported by the Gorgan University of Agricultural Sciences and Natural Resources.

\section{Authors' Contributions}

$\mathrm{HB}$ and MK conceived and carried out the study. HB carried out textural test, statistical analysis and wrote the manuscript. MK reviewed the manuscript.

\section{Ethical Approval}

The study protocols and procedures were ethically approved by the Ethical Committee of Gorgan University of Agricultural Sciences and Natural Resources.

\section{References}

1. Hu Y, Shim YY, Reaney MJ. Flaxseed Gum Solution Functional Properties. Foods. 2020;9(5):681.

2. Upadhyay R, Ghosal D, Mehra A. Characterization of bread dough: Rheological properties and microstructure. Journal of Food Engineering. 2012;109(1):104-13.

3. Norton T, Sun DW. Recent advances in the use of high pressure as an effective processing technique in the food industry. Food and Bioprocess Technology. 2008;1(1):2-34.

4. Teng LY, Chin NL, Yusof YA. Rheological and textural studies of fresh and freeze-thawed native sago starch-sugar gels. II. Comparisons with other starch sources and reheating effects. Food Hydrocolloids. 2013;31(2):156-65.

5. Maity T, Saxena A, Raju PS. Use of hydrocolloids as cryoprotectant for frozen foods. Critical reviews in food science and nutrition. 2018;58(3):420-35.

6. Marcotte M, Hoshahili AR, Ramaswamy HS. Rheological properties of selected hydrocolloids as a function of concentration and temperature. Food Research International. 2001;34(8):695-703.

7. Koocheki A, Taherian AR, Razavi SM, Bostan A. Response surface methodology for optimization of extraction yield, viscosity, hue and emulsion stability of mucilage extracted 
from Lepidium perfoliatum seeds. Food Hydrocolloids. 2009;23(8):2369-79.

8. Bagheri, H., Graili, Z., Kashaninezhad, M. Evaluation rheological of Qudomeh shahri a function of concentration and freezing process and compare it's with commercial Xanthan gum. Innovative Food Technologies. 2015;3(1):3342.

9. Bagheri H, Koochaki A, Mohebi M. Effects of Leidium perfoliatum seed and xanthan gums on physical properties of pan bread. Food Science and Technology. 2016;13(58):11729.

10. Palaniraj A, Jayaraman V. Production, recovery and applications of xanthan gum by Xanthomonas campestris. Journal of Food Engineering. 2011;106(1):1-2.

11. Behrouzian F, Razavi SM, Karazhiyan H. The effect of $\mathrm{p} \mathrm{H}$, salts and sugars on the rheological properties of cress seed (L epidium sativum) gum. International journal of food science \& technology. 2013;48(12):2506-13.

12. Zeira A, Nussinovitch A. Mechanical properties of weak locust bean gum (lbg) gels under controlled rapid freezethawing. Journal of texture studies. 2003;34(5-6):561-73.

13. Naji S, Razavi SM, Karazhiyan H. Effect of freezing on functional and textural attributes of cress seed gum and xanthan gum. Food and Bioprocess Technology. 2013;6(5):1302-11.

14. Maity T, Chauhan OP, Shah A, Raju PS, Bawa AS. Quality characteristics and glass transition temperature of hydrocolloid pre-treated frozen pre-cut carrot. International Journal of Food Properties. 2011;14(1):17-28.

15. Zeynali M, Naji-Tabasi S, Farahmandfar R. Investigation of basil (Ocimum bacilicum L) seed gum properties as Cryoprotectant for Frozen Foods. Food Hydrocolloids. 2019;90:305-312.

16. Saha D, Bhattacharya S. Characteristics of gellan gum based food gels. Journal of texture studies. 2010;41(4):459-71.

17. Soma PK, Williams PD, Lo YM. Advancements in non-starch polysaccharides research for frozen foods and microencapsulation of probiotics. Frontiers of Chemical Engineering in China. 2009;3(4):413.

18. Koocheki A, Taherian AR, Bostan A. Studies on the steady shear flow behavior and functional properties of Lepidium perfoliatum seed gum. Food Research International. 2013 Jan 1;50(1):446-56.

19. Lee MH, Baek MH, Cha DS, Park HJ, Lim ST. Freeze-thaw stabilization of sweet potato starch gel by polysaccharide gums. Food hydrocolloids. 2002;16(4):345-52.

20. Park SH, Hong GP, Kim JY, Choi MJ, Min SG. The influence of food hydrocolloids on changes in the physical properties of ice cream. Food Science and Biotechnology. 2006;15(5):7217.

21. Freitas F, Alves VD, Carvalheira M, Costa N, Oliveira R, Reis MA. Emulsifying behaviour and rheological properties of the extracellular polysaccharide produced by Pseudomonas oleovorans grown on glycerol byproduct. Carbohydrate Polymers. 2009;78(3):549-56.

22. Roopa BS, Bhattacharya S. Alginate gels: II. Stability at different Processing conditions. Journal of food process engineering. 2010;33(3):466-80.

23. Zameni A, Kashaninejad M, Aalami M, Salehi F. Effect of thermal and freezing treatments on rheological, textural and color properties of basil seed gum. Journal of food science and technology. 2015;52(9):5914-21

24. Angioloni A, Collar C. Small and large deformation viscoelastic behaviour of selected fibre blends with gelling properties. Food Hydrocolloids. 2009;23(3):742-8.

25. Bagheri H, Kashaninejad M, Ziaiifar AM, Aalami M. Novel hybridized infrared-hot air method for roasting of peanut kernels. Innovative Food Science \& Emerging Technologies. 2016;37:106-14

26. Hosseini-Parvar SH, Matia-Merino L, Goh KK, Razavi SM, Mortazavi SA. Steady shear flow behavior of gum extracted from Ocimum basilicum L. seed: Effect of concentration and temperature. Journal of Food Engineering. 2010;101(3):23643.

27. Sae-kang V, Suphantharika M. Influence of $\mathrm{pH}$ and xanthan gum addition on freeze-thaw stability of tapioca starch pastes. Carbohydrate Polymers. 2006;65(3):371-80.

28. Williams PD, Sadar LN, Martin Lo Y. Texture stability of hydrogel complex containing curdlan gum over multiple freeze-thaw cycles. Journal of Food Processing and Preservation. 2009;33(1):126-39.

29. Basu S, Shivhare US. Rheological, textural, micro-structural and sensory properties of mango jam. Journal of Food Engineering. 2010;100(2):357-65.

30. Salehi F, Kashaninejad M. Effect of different drying methods on rheological and textural properties of Balangu seed gum. Drying Technology. 2014;32(6):720-7.

31. Faydi E, Andrieu J, Laurent P. Experimental study and modelling of the ice crystal morphology of model standard ice cream. Part I: Direct characterization method and experimental data. Journal of food engineering. 2001;48(4):283-91.

32. Irani M, Razavi SM, Abdel-Aal ES, Hucl P, Patterson CA. Viscoelastic and textural properties of canary seed starch gels in comparison with wheat starch gel. International journal of biological macromolecules. 2019;124:270-81.

33. Bagheri H, Avazsufiyan A, Alami M. Evaluation of the effect of guar and xanthan gums on viscoelastic properties of glutenfree sponge cake by the use of stress relaxation test. Journal of Food Technology and Nutrition, 2017;15(1):101-109.

34. Fiszman SM, Damasio MH. Suitability of single-compression and TPA tests to determine adhesiveness in solid and semisolid foods. Journal of texture studies. 2000;31(1):55-68. 